\title{
PHASES IDENTIFICATION BY X- RAY ANALYSIS FOR LIQUID PHASE SINTERED TUNGSTEN HEAVY ALLOYS
}

\author{
A. S. Abdallah ${ }^{1}$, A. Fayed ${ }^{2}$, G. M. Abdo ${ }^{3}$, M. Tolba Sallam ${ }^{4}$ \\ ${ }^{1}$ Dr.Engineer, Technical Research Center \\ ${ }^{2}$ Dr.Eng, Military Technical College \\ ${ }^{3}$ Dr.Eng, Technical Research Center \\ ${ }^{4}$ Prof. Dr.Eng, Military Technical College
}

\begin{abstract}
The objective of this experimental study is to determine and analyze the phases present in tungsten heavy alloy specimens of different chemical compositions and to follow up the evolution of these phases during sintering using X-ray diffraction. On the other hand, $X$-ray diffraction graphs was used to reveal the effect of sintering parameters and alloy composition on the nature of the diffusion processes that take place among the different constituents present in the alloy.

The X-ray diffraction analysis started by the determination of the diffraction patterns of pure elements of the constituents of the alloys used in this experimental study. Then, the X-ray diffraction analysis was performed for liquid phase sintered tungsten heavy alloy, having the composition $93 \% \mathrm{~W}-4.9 \% \mathrm{Ni}-2.1 \% \mathrm{Fe}$, and sintered at different temperatures. Also, to determine the effect of addition of Cobalt to the matrix constituents, X-ray diffraction pattern obtained using tungsten heavy alloy having the composition $91 \% \mathrm{~W}$ - 6\% $\mathrm{Ni}-3 \% \mathrm{Co}$ was compared with that for the basic alloy prepared in the same conditions.
\end{abstract}

$X R D$ results obtained for this alloy sintered at different temperatures confirmed that with increasing the sintering temperature, the tungsten solubility in the matrix increases resulting in a pronounced solid solution strengthening. Also, the study proves that the presence of cobalt in the solid solution of the matrix suppresses the solubility of tungsten in this matrix.

Keywords: Tungsten heavy alloy, X-ray diffraction, Diffraction patterns.

\section{INTRODUCTION}

Tungsten Heavy Alloys (WHAs) are two phase metal matrix composites that typically contain 90 to $98 \mathrm{wt} \% \mathrm{~W}$, in combination with some mix of nickel, iron, copper, and/or cobalt. Some alloying elements are added as Mo, Ta, Re and $\mathrm{Cr}, \ldots$ etc for improving the alloy properties. The principal phase, being hard, is the pure tungsten, in association with a ductile binder phase containing the transition metals plus some dissolved tungsten[1].

As a consequence, WHAs derives their fundamental properties from those of the principal tungsten phase, which provides both the high density and the high elastic stiffness. Nickel, iron, cobalt and copper serve as a binder matrix, which holds the brittle tungsten grains together and makes tungsten alloys ductile and easy to machine. Which gives sintered WHAs a unique combination of properties [1].

The choice of composition is driven by several considerations. The primary factor is the density required by the given application. Further considerations include corrosion resistance, magnetic character, mechanical properties. This alloy composition determines the post sintering heat treatment options [2].

The majority of current uses for WHAs are best satisfied with the W-Ni-Fe system. Nickel-iron is the most popular binder additive, and it was found that a ratio of $7 \mathrm{Ni}: 3 \mathrm{Fe}$ or $8 \mathrm{Ni}: 2 \mathrm{Fe}$ (by weight)[3] is the most adequate for optimum mechanical properties. It is also known that the composition ratio of alloying additions to tungsten must be kept within a range that avoids formation of intermetallic compounds which causes embrittlement in the alloy. For example, in the commercially important tungsten-nickel-iron alloy system the nickel to iron ratio is generally held within the range of about $1: 1$ to $4: 1$. Outside this range, brittle intermetallic phases form in the binder phase which rapidly degrade the properties[4,5,6].

The propensity of the iron and nickel alloys to form an intermetallic phase with tungsten is well known. At low nickel to iron ratios the excess iron forms a series of intermetallic phases, $\mathrm{Fe}_{7} \mathrm{~W}_{6}$ known as $(\mu)$ phase which is stable below a temperature of about $1637^{\circ} \mathrm{C}$, down to a temperature of about $1190^{\circ} \mathrm{C}$, and may be retained at room temperature [7], in addition to $\mathrm{Fe}_{2} \mathrm{~W}$ known as $(\lambda)$ phase and $\mathrm{FeW}$ known as $(\delta)$ phase which may persist to room temperature as shown in Fig.(1).

Above the ratio of about 4:1 nickel to iron, (excess nickel) a series of Ni:W intermetallics can also be formed, including $\mathrm{NiW}_{2}, \mathrm{NiW}$ and $\mathrm{Ni}_{4} \mathrm{~W}$ which are stable below about $1000^{\circ} \mathrm{C}$ down to room temperature as shown in Fig.(2) [7]. 
The addition of cobalt to a W-Ni-Fe alloy is a common approach for enhancement of both strength and ductility. The presence of cobalt within the alloy provides, from one hand, solid-solution strengthening of the binder, leading to increasing the strength and hardness of the matrix and, from the other hand, improves wettability of liquid matrix for tungsten grains, thus enhancing tungsten-matrix interfacial strength. Cobalt additions of 5 to $47.5 \%$ of the nominal binder weight fraction are most common [4].

Furthermore, W-Ni-Co system with nickel-to-cobalt ratios ranging from 9 to 2[4] could be used for extremely demanding applications, where higher mechanical properties are required. Due to the presence of cobalt and during cooling down from the sintering temperature, tungsten with cobalt form a series of intermetallic compounds $\left(\mathrm{Co}_{3} \mathrm{~W}\right.$, $\mathrm{Co}_{7} \mathrm{~W}_{6}$ ) as in the binary phase diagram shown in Fig.(3). These compounds have deep harmful influence, from one hand, on the mechanical properties of the matrix phase particularly its ductility, and from the other hand on the interfacial strength between the matrix phase and the hard tungsten particles.

The increasing amount of these different intermetallic compounds formed between the matrix ingredients and the tungsten particles deteriorate the mechanical properties and limit the applications of these alloys. That is why it is not recommended to use these alloys in the as sintered state particularly when cobalt is added to the alloy composition [4], and it is ultimately necessary to apply particular heat treatments in order to minimize the presence of such compounds [8].

The effects of sintering temperature on mechanical properties are essentially attributed to the resulting variations in grain size, matrix volume fraction and contiguity [9], the later defines the contiguity of tungsten grains in tungsten alloy defined as the relative fraction of tungsten-tungsten interfacial area.

The main focus of this study is to investigate and identify the effect of sintering temperature and alloy composition on the sintering process using X-ray diffraction graphs.

\section{EXPERIMENTAL PROCEDURE}

\subsection{Characteristics of Used Powders}

The main constituents of the adopted tungsten heavy metal alloy are commercial pure tungsten, nickel, cobalt and iron powders. The different powders were chemically analyzed by X-ray fluorescence (XRF) technique to determine their composition and purity. The obtained chemical compositions are illustrated in Table (1).

Table 1: Chemical composition of the used powders (in wt.\%)

\begin{tabular}{|l|l|l|l|l|l|l|l|l|l|l|l|l|}
\hline $\begin{array}{l}\text { Composition } \\
\text { Powders }\end{array}$ & $\mathrm{W} \%$ & $\mathrm{Ni} \%$ & $\mathrm{Fe} \%$ & $\mathrm{Si} \%$ & $\mathrm{Al} \%$ & $\mathrm{Mg} \%$ & $\mathrm{Ca} \%$ & $\mathrm{Ga} \%$ & $\mathrm{P} \%$ & $\mathrm{~S} \%$ & $\mathrm{Na} \%$ & $\mathrm{~F} \%$ \\
\hline $\begin{array}{l}\text { Tungsten } \\
\text { powder }\end{array}$ & 99.825 & -- & -- & -- & -- & -- & 0.036 & 0.021 & 0.062 & 0.056 & -- & -- \\
\hline $\begin{array}{l}\text { Nickel } \\
\text { powder }\end{array}$ & -- & 99.496 & 0.132 & 0.204 & 0.115 & 0.046 & -- & -- & 0.003 & 0.003 & -- & -- \\
\hline Iron powder & -- & -- & 99.396 & 0.335 & 0.172 & 0.062 & 0.02 & -- & 0.01 & 0.005 & -- & -- \\
\hline $\begin{array}{l}\text { Cobalt } \\
\text { powder }\end{array}$ & -- & -- & -- & 0.06 & 0.02 & 0.02 & -- & -- & -- & -- & 0.01 & 1.14 \\
\hline
\end{tabular}

The apparent densities of these powders were measured by Hall flowmeter, and the tap densities were determined after standard tapping. The results of both densities were compared with the values of the theoritical densities as shown in Table (2).

Table 2: Theoritical, apparent and tap densities of the used powders

\begin{tabular}{|l|l|l|l|l|}
\hline $\begin{array}{l}\text { Powders } \\
\text { Measured density }\end{array}$ & $\begin{array}{l}\text { Tungsten } \\
\text { powder }\end{array}$ & $\begin{array}{l}\text { Nickel } \\
\text { powder }\end{array}$ & $\begin{array}{l}\text { Iron } \\
\text { powder }\end{array}$ & $\begin{array}{l}\text { Cobalt } \\
\text { powder }\end{array}$ \\
\hline Apparent density, g/cc & 3.6 & 0.93 & 1.4 & 1.3 \\
\hline Tap density, g/cc & 6.75 & 1.65 & 2.63 & 2.4 \\
\hline Theoretical density, g/cc & 19.3 & 8.9 & 7.9 & 8.8 \\
\hline
\end{tabular}

The morphology and the particle size of the used powders were revealed by SEM as shown in Fig.1(a-d). Tungsten powder appered to have polygonal shape, nickel powder is of spongy shape, cobalt powder has flake shape, while the iron powder shows nearly spherical shape. It can be noted that Tungsten, Nickel, Cobalt and Iron powders have an average particle size of about 1-2 $\mu \mathrm{m}, 1-3 \mu \mathrm{m}, 1-3 \mu \mathrm{m}$ and 3-5 $\mu \mathrm{m}$ respectivily. 


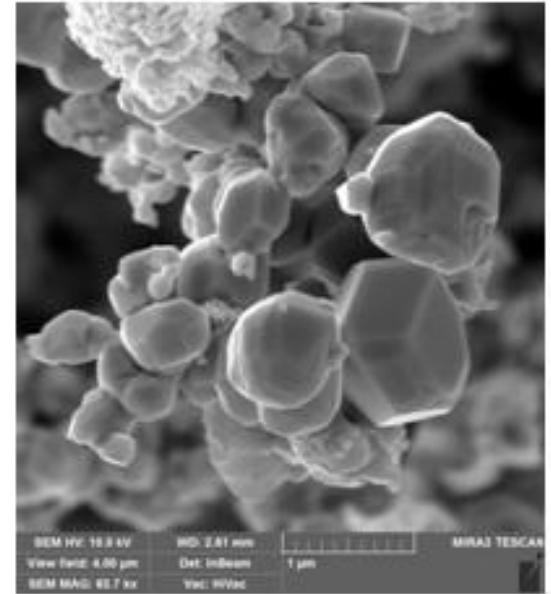

(a)

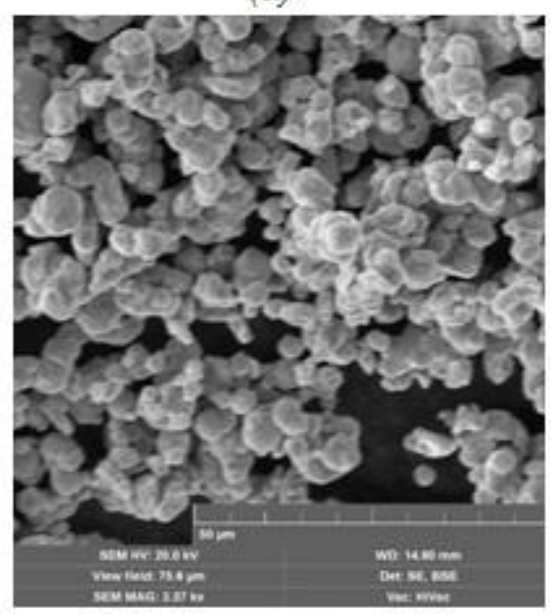

(c)

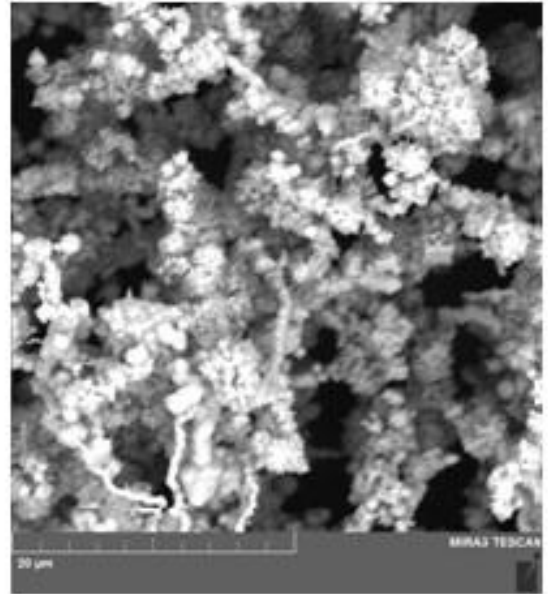

(b)

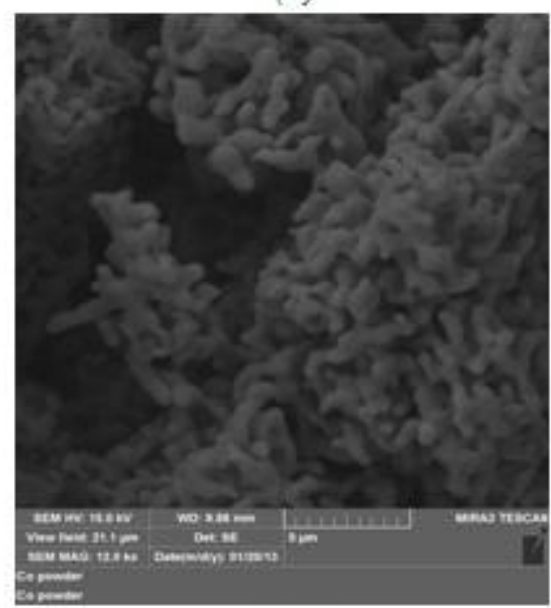

(d)

Fig.1: SEM images of as received (a) Tungsten, (b) Nickel, (c) Iron, and (d) Nickel powders

\subsection{Preparation of Sintered Specimens}

For this objective, two different compositions were prepared as follows: The first alloy has the composition $93 \% \mathrm{~W}-$ $4.9 \% \mathrm{Ni}-2.1 \% \mathrm{Fe}$, while, the second alloy has the composition $91 \% \mathrm{~W}-6 \% \mathrm{Ni}-3 \% \mathrm{Co}$, where, the iron is substituted completely with cobalt, which represents about $33 \%$ of the amount of the binder.

The different powders were mixed using double cone mixer for 2 hours, to insure homogeneous mixing. The powders were then shaped into flat specimens and subjected to an uni-axial compaction pressure of 200MPa. All the compacted samples were also sintered in a vacuum atmosphere. Sintering temperature was varied from $1470^{\circ} \mathrm{C}$ up to $1510^{\circ} \mathrm{C}$ for a period of 90 minutes.

\subsection{Phases Identification by X-ray Analysis}

Samples were prepared for evaluation by cutting, mounting, grinding and polishing to a $0.3 \mu \mathrm{m}$ surface finish using standard metallographic procedures. An X-ray diffraction equipment type X'Pert PRO PAN analytical was used.

\section{RESULTS AND DISCUSSION}

X-ray diffraction was used to determine and analyze the phases present in tungsten heavy alloy specimens of different chemical compositions and to follow up the evolution of these phases during sintering. On the other hand, X-ray diffraction graphs was used to reveal the effect of sintering parameters, alloy composition and heat treatment on the nature of the diffusion processes that take place among the different constituents present in the alloy.

\subsection{X-ray Diffraction Analysis for Pure Elements}

The X-ray diffraction analysis was started by the determination of the diffraction patterns of pure elements of the base powders used in the different alloys namely tungsten, nickel, iron and cobalt.

The X-ray diffraction pattern obtained from the as received tungsten powder is illustrated in Fig.(2). The pattern reveals a maximum diffraction peak with $100 \%$ intensity at $2 \theta=40.416^{\circ}$ obtained by the crystallographic plane (110). Also, we can clearly note the occurrence of two other peaks of nearly the same intensity at $2 \theta$ angles $73.33^{\circ}$ and $132.99^{\circ}$ obtained by the diffraction on the crystallographic planes 
(211) and (321) respectively. Furthermore, another series of lower intensity peaks can be observed at various $2 \theta$ positions as indicated in Fig.(2) and Table (3).

The diffraction pattern obtained from the as received nickel powder is shown in Fig.(3). We can clearly note a maximum diffraction peak at $2 \theta=44.508^{\circ}$ obtained by the diffraction on the crystallographic plane (111) followed by another peak at $2 \theta=51.847^{\circ}$ of nearly half the maximum intensity obtained by the diffraction on the crystallographic plane (200). Furthermore, another series of lower intensity peaks can be observed at various $2 \theta$ positions as indicated in Fig.(3) and Table (4).

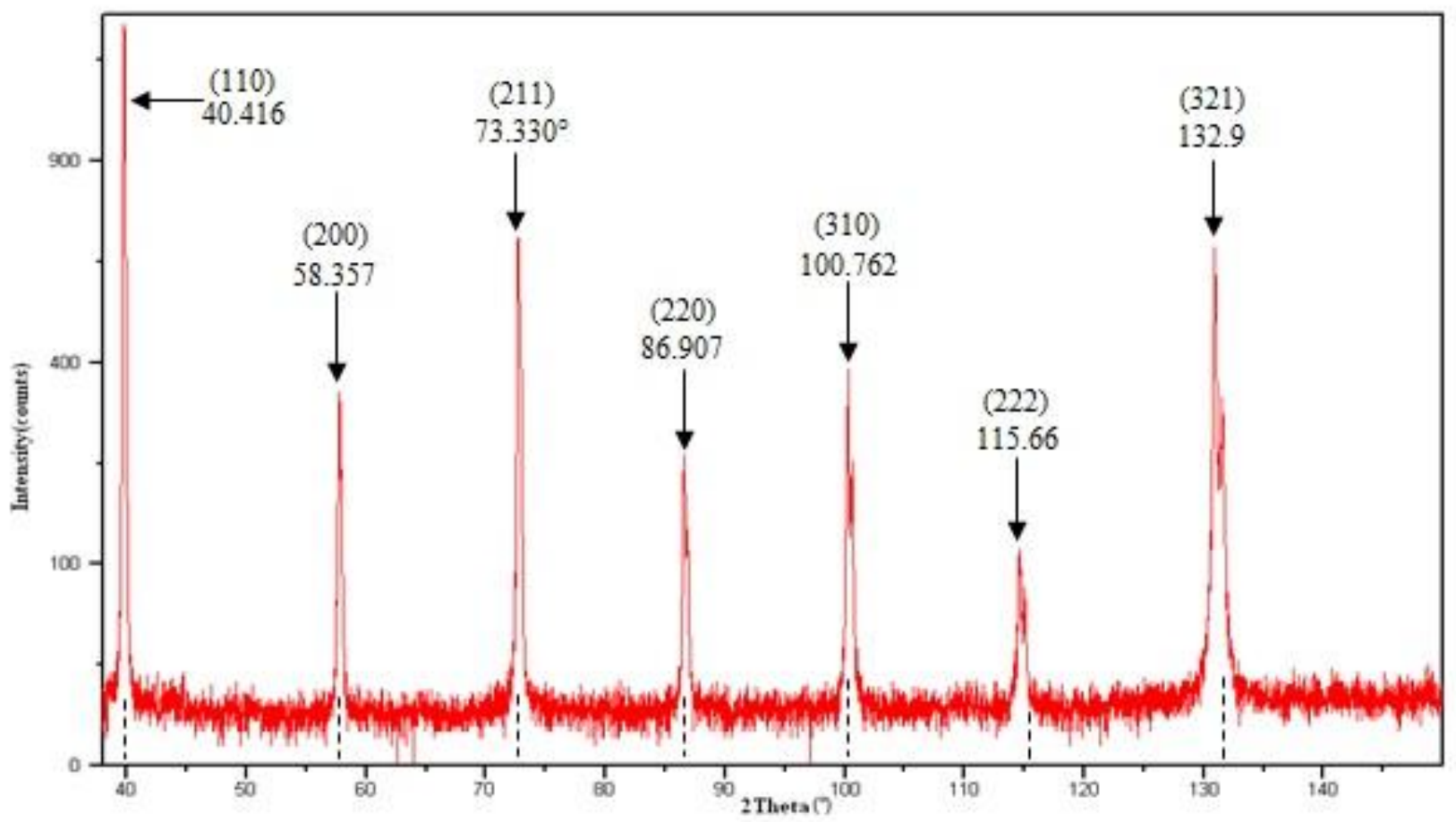

Fig 2: XRD pattern of Tungsten powder

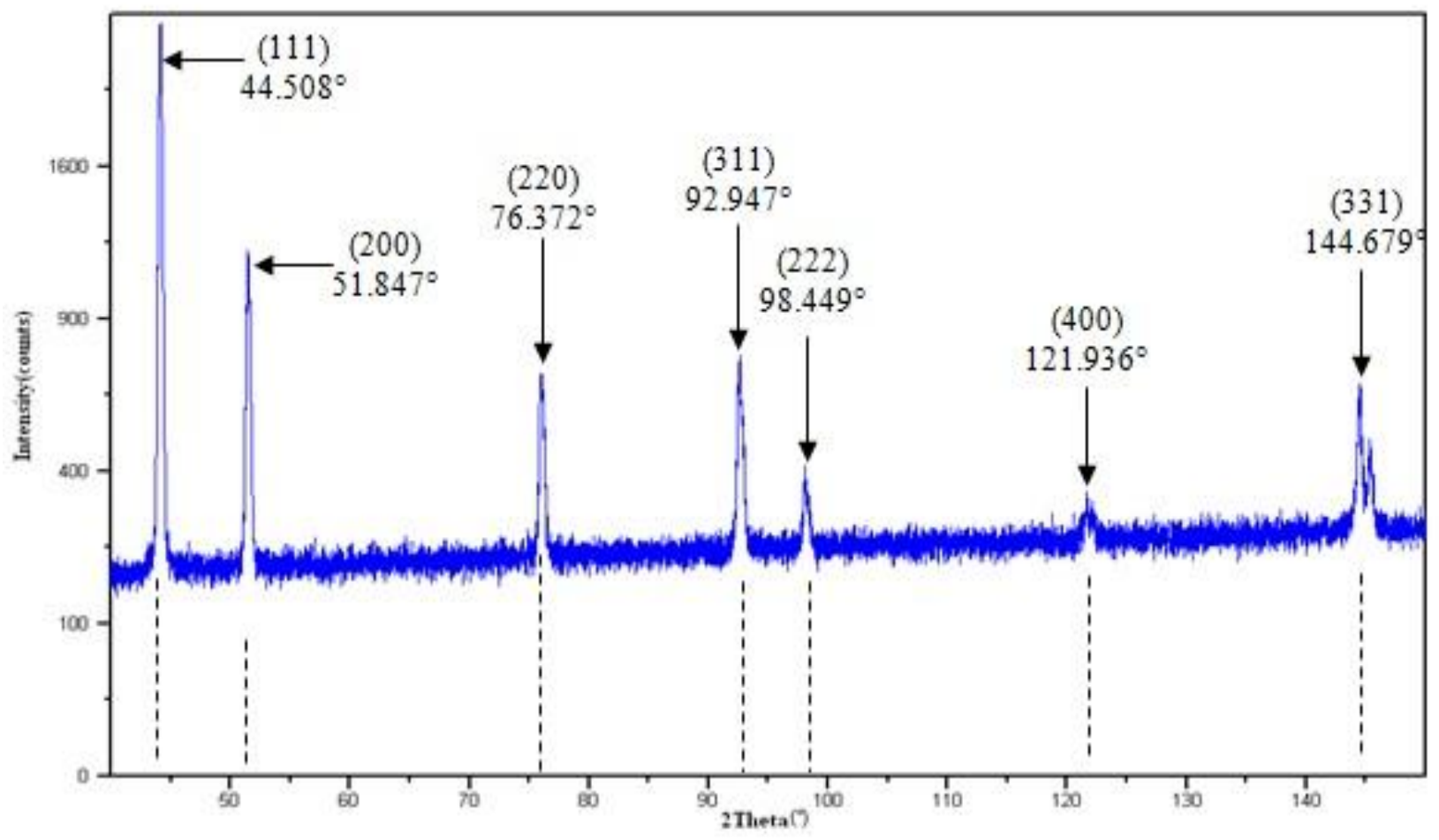

Fig 3: XRD pattern of Nickel powder. 
Table 3: Tungsten powder diffraction results

\begin{tabular}{|l|l|l|l|}
\hline Powder type & $\begin{array}{l}\text { Position } \\
2 \theta\end{array}$ & hkl & $\begin{array}{l}\text { Intensity } \\
\%\end{array}$ \\
\hline \multirow{5}{*}{ Tungsten (W) } & 40.416 & $(110)$ & 100 \\
\cline { 2 - 4 } & 58.357 & $(200)$ & 63 \\
\cline { 2 - 4 } & 73.33 & $(211)$ & 75 \\
\cline { 2 - 4 } & 86.907 & $(220)$ & 63 \\
\cline { 2 - 4 } & 100.762 & $(310)$ & 75 \\
\cline { 2 - 4 } & 115.662 & $(222)$ & 38 \\
\cline { 2 - 4 } & 132.99 & $(321)$ & 63 \\
\hline
\end{tabular}

Table 4: Nickel powder diffraction results

\begin{tabular}{|l|l|l|l|}
\hline Powder type & $\begin{array}{l}\text { Position } \\
2 \theta\end{array}$ & hkl & $\begin{array}{l}\text { Intensity } \\
\%\end{array}$ \\
\hline \multirow{5}{*}{ Nickel (Ni) } & 44.508 & $(111)$ & 100 \\
\cline { 2 - 4 } & 51.847 & $(200)$ & 42 \\
\cline { 2 - 4 } & 76.372 & $(220)$ & 21 \\
\cline { 2 - 4 } & 92.947 & $(311)$ & 20 \\
\cline { 2 - 4 } & 98.449 & $(222)$ & 7 \\
\cline { 2 - 4 } & 121.936 & $(400)$ & 4 \\
\cline { 2 - 4 } & 144.679 & $(331)$ & 14 \\
\hline
\end{tabular}

The X-ray diffraction pattern obtained from the as received iron powder is illustrated in Fig.(4). The pattern reveals a maximum diffraction peak at $2 \theta=44.6^{\circ}$ obtained by the crystallographic plane (110). We can also clearly note the formation of another peak at $2 \theta$ position of $82.352^{\circ}$ obtained by the diffraction on the_crystallographic plane (211) having an intensity of $80 \%$ of the maximum one. Along the same XRD pattern, it can also be visualized another series of diffraction peaks of lower intensity at different $2 \theta$ positions as indicated in Fig.(4) and Table (5).

The diffraction pattern obtained from the as received cobalt powder is shown in Fig.(5). We can distinguish a maximum intensity peak obtained by the crystallographic plane (002) at $2 \theta=44.6^{\circ}$. Furthermore, the XRD pattern reveals also two peaks of intensity in the order of $60 \%$ of the maximum intensity obtained at $2 \theta=51.08^{\circ}$ and $77.8^{\circ}$ from the diffraction on the crystallographic planes (200) and (222). Moreover, another group of lower intensity peaks can be observed at various $2 \theta$ positions as indicated in Fig.(5) and Table (6).

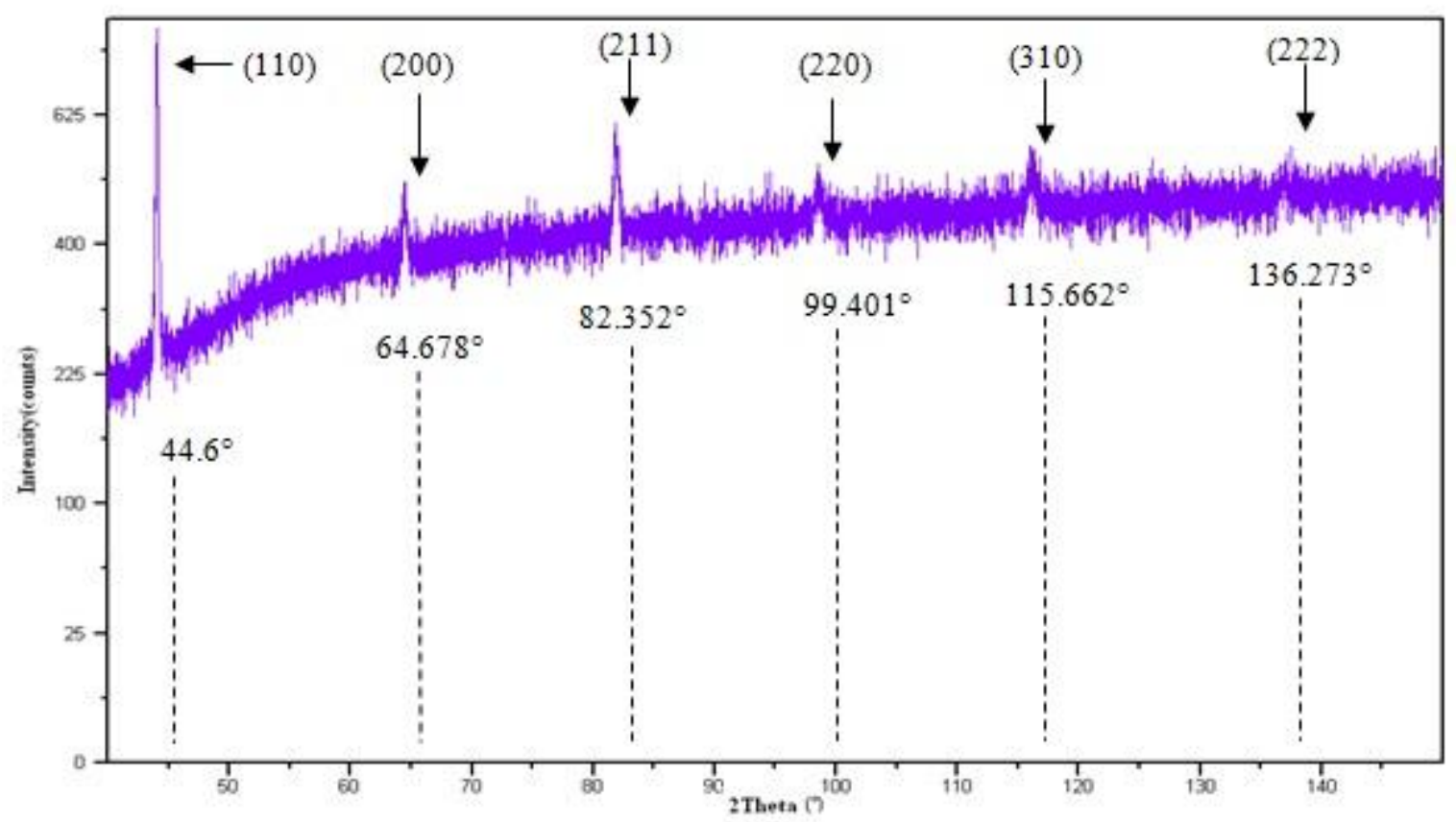

Fig 4: XRD pattern of Iron powder. 


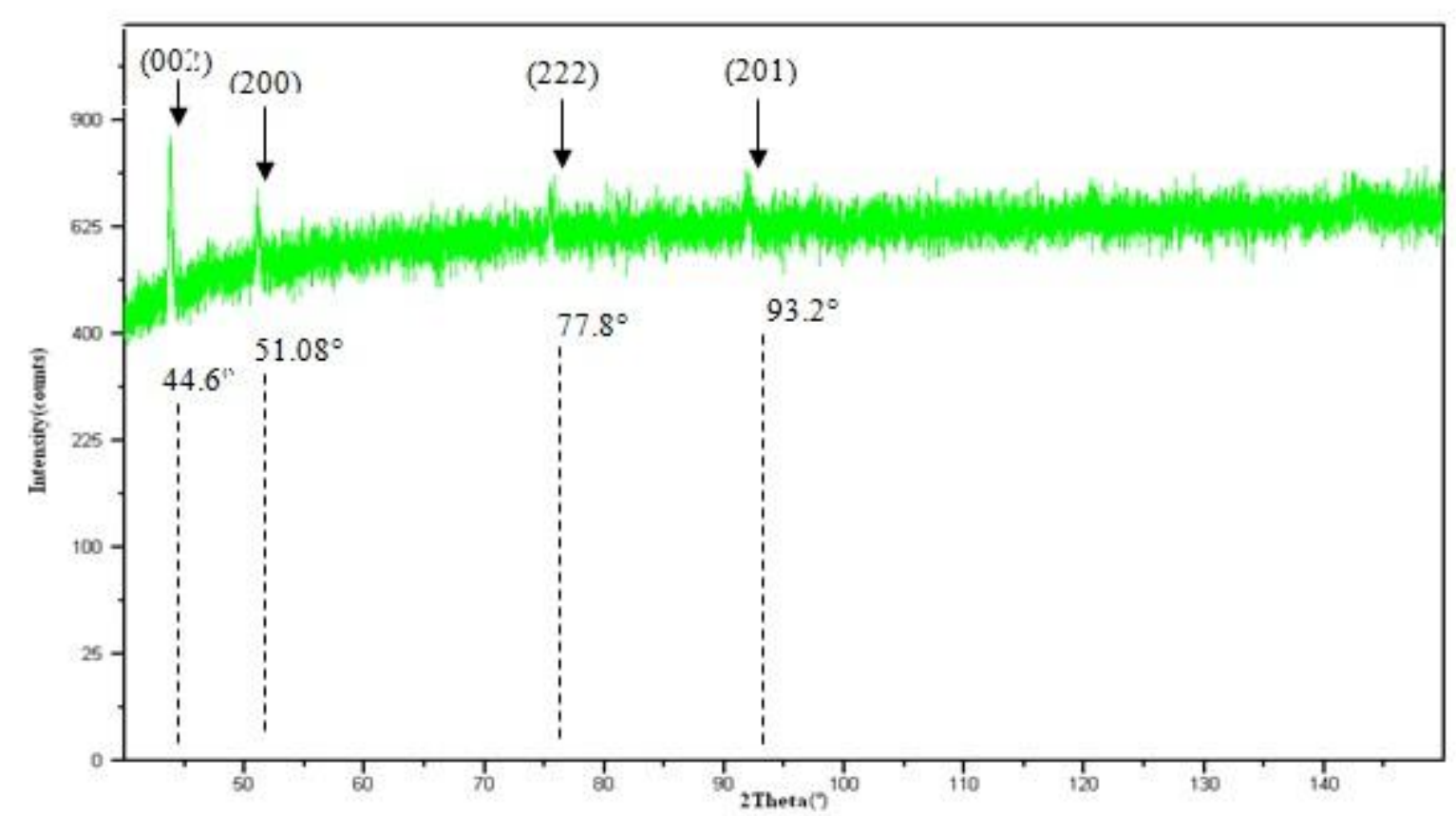

Fig 5: XRD pattern of Cobalt powder.

Table 5: Iron powder diffraction results

\begin{tabular}{|l|l|l|l|}
\hline $\begin{array}{l}\text { Powder } \\
\text { type }\end{array}$ & Position $2 \theta$ & hkl & Intensity \% \\
\hline \multirow{5}{*}{ Iron (Fe) } & 44.6 & $(110)$ & 100 \\
\cline { 2 - 4 } & 64.678 & $(200)$ & 50 \\
\cline { 2 - 4 } & 82.352 & $(211)$ & 80 \\
\cline { 2 - 4 } & 99.401 & $(220)$ & 50 \\
\cline { 2 - 4 } & 115.662 & $(310)$ & 60 \\
\cline { 2 - 4 } & 136.273 & $(222)$ & 20 \\
\hline
\end{tabular}

Table 6: Cobalt powder diffraction results

\begin{tabular}{|l|l|l|l|}
\hline $\begin{array}{l}\text { Powder } \\
\text { type }\end{array}$ & Position $2 \theta$ & hkl & Intensity \% \\
\hline \multirow{5}{*}{$\begin{array}{l}\text { Cobalt } \\
(\text { Co })\end{array}$} & 44.6 & $(002)$ & 100 \\
\cline { 2 - 4 } & 51.08 & $(200)$ & 60 \\
\cline { 2 - 4 } & 76.2 & $(100)$ & 40 \\
\cline { 2 - 4 } & 77.8 & $(222)$ & 63 \\
\cline { 2 - 4 } & 93.2 & $(201)$ & 30 \\
\cline { 2 - 4 } & 98.2 & $(004)$ & 5 \\
\hline
\end{tabular}

\subsection{X-ray Diffraction Analysis at Different}

\section{Sintering Temperatures}

Figs.(6) and (7) demonstrate the X-ray diffraction patterns obtained using tungsten heavy alloy having the composition $93 \% \mathrm{~W}-4.9 \% \mathrm{Ni}-2.1 \% \mathrm{Fe}$ uni-axially compacted under 200 $\mathrm{MPa}$ and sintered for 90 minutes at $1470^{\circ} \mathrm{C}$ and $1510^{\circ} \mathrm{C}$ respectively. XRD examination clarifies only two phases in the alloy, BCC structured W-rich phase and FCC structured $\mathrm{NiFe}$-rich phase as shown in Figs.(6) and (7). 


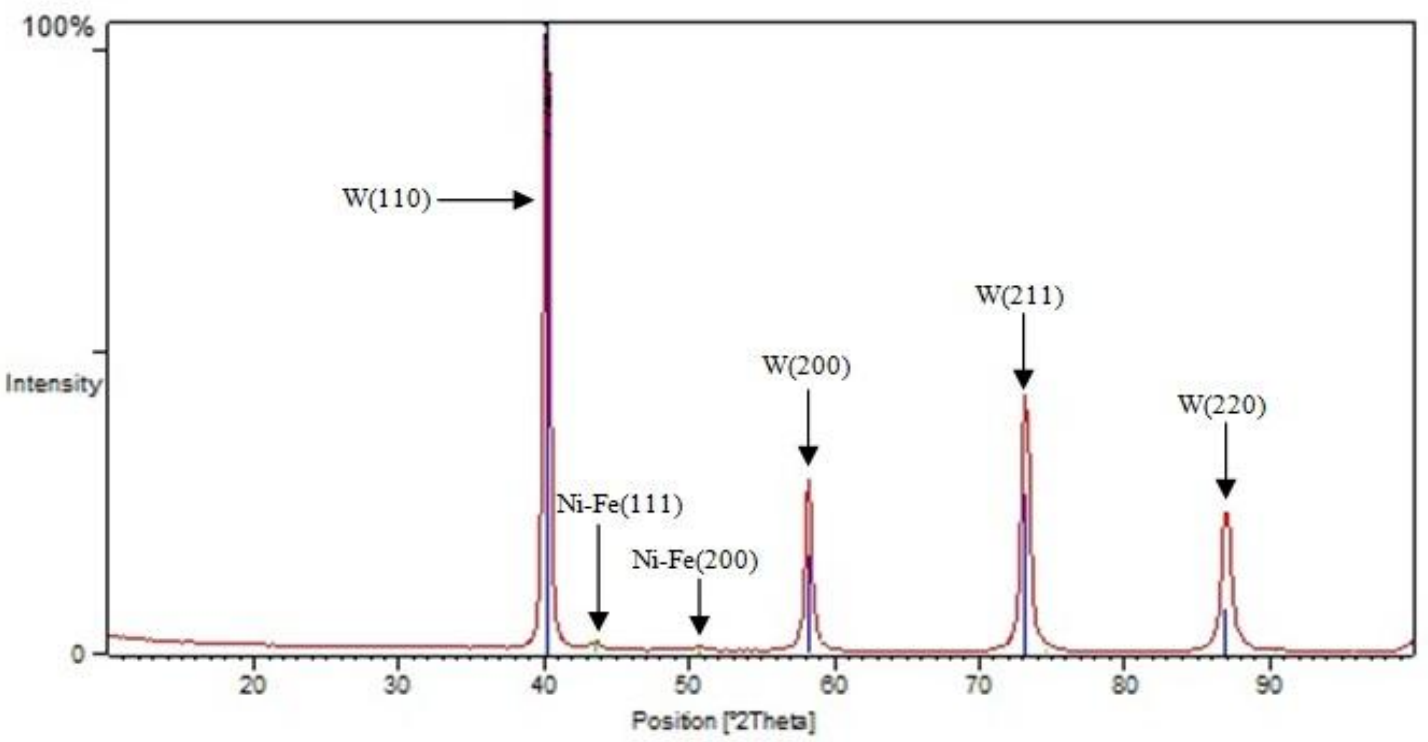

Fig 6: X-ray diffraction pattern obtained using tungsten heavy alloy having the composition $93 \% \mathrm{~W}-4.9 \% \mathrm{Ni}-2.1 \% \mathrm{Fe}$ uni-axially compacted under $200 \mathrm{MPa}$ and sintered for 90 minutes at $1470^{\circ} \mathrm{C}$.

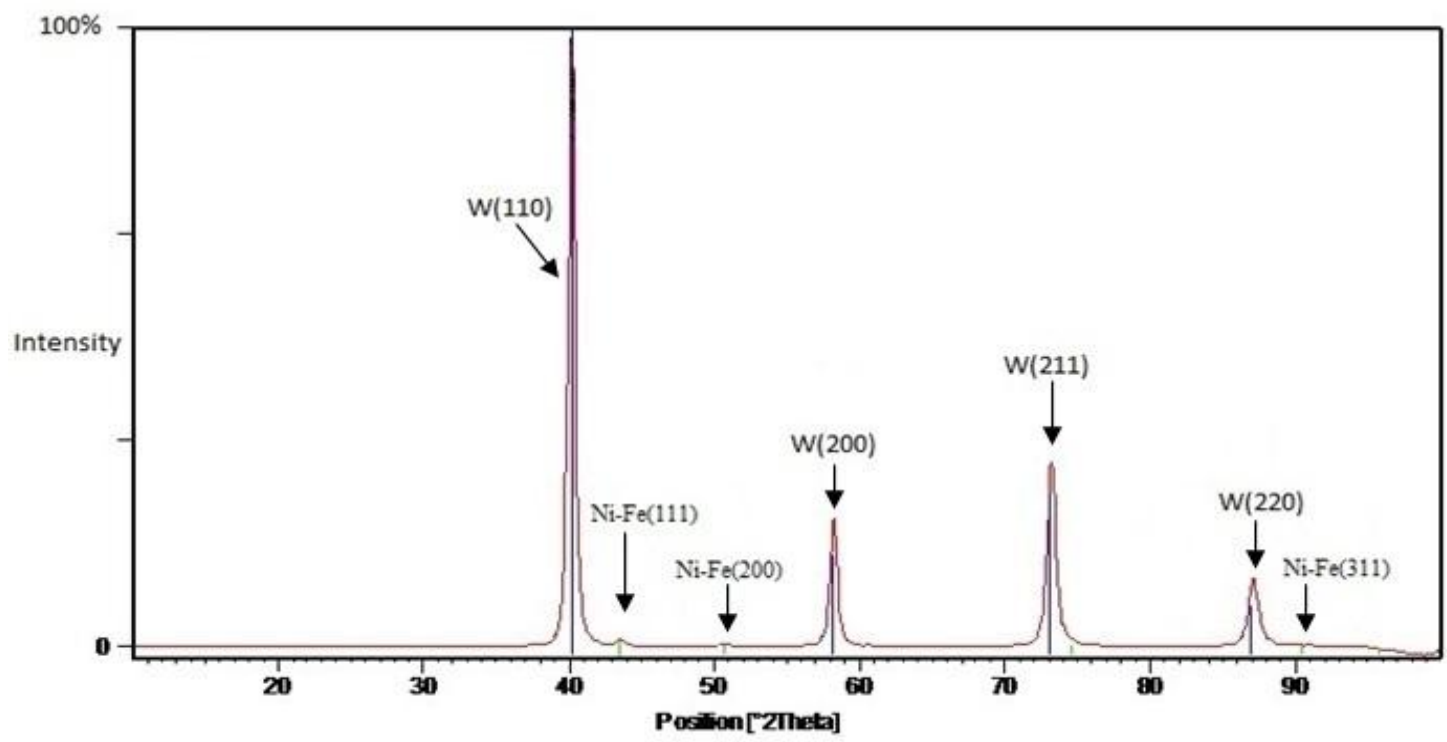

Fig 7: X-ray diffraction pattern obtained using tungsten heavy alloy having the composition $93 \% \mathrm{~W}-4.9 \% \mathrm{Ni}-2.1 \% \mathrm{Fe}$ uni-axially compacted under $200 \mathrm{MPa}$ and sintered for 90 minutes at $1510^{\circ} \mathrm{C}$.

The diffraction peaks and their corresponding position $2 \theta$ for the previous patterns obtained for W-Ni-Fe based heavy alloy at different sintering temperatures together with their relative intensities are shown in Table (7) and Table (8).

Table 7: Diffraction results obtained from W-Ni-Fe sintered at $1470^{\circ} \mathrm{C}$

\begin{tabular}{|l|l|l|l|l|}
\hline No. & Phase & Diffraction plane & Position $2 \theta$ & $\begin{array}{l}\text { Relative } \\
\text { intensity } \%\end{array}$ \\
\hline 1 & W & 110 & 40.2146 & 100 \\
\hline 2 & Ni-Fe & 111 & 43.6733 & 1.15 \\
\hline 3 & Ni-Fe & 200 & 50.6378 & 0.37 \\
\hline 4 & W & 200 & 58.2366 & 27.29 \\
\hline 5 & W & 211 & 73.1811 & 40.74 \\
\hline 6 & W & 220 & 86.9623 & 21.48 \\
\hline
\end{tabular}


Table 8: Diffraction results obtained from W-Ni-Fe sintered at $1510^{\circ} \mathrm{C}$

\begin{tabular}{|l|l|l|l|l|}
\hline No. & Phase & Diffraction plane & Position $2 \theta$ & $\begin{array}{l}\text { Relative } \\
\text { intensity } \%\end{array}$ \\
\hline 1 & W & 110 & 40.2534 & 100 \\
\hline 2 & $\mathrm{Ni}-\mathrm{Fe}$ & 111 & 43.509 & 1.09 \\
\hline 3 & $\mathrm{Ni}-\mathrm{Fe}$ & 200 & 50.576 & 0.24 \\
\hline 4 & $\mathrm{~W}$ & 200 & 58.2588 & 21.04 \\
\hline 5 & $\mathrm{~W}$ & 211 & 73.2051 & 30.28 \\
\hline 6 & $\mathrm{~W}$ & 220 & 87.0949 & 11.23 \\
\hline 7 & $\mathrm{Ni}-\mathrm{Fe}$ & 311 & 93.4778 & 0.04 \\
\hline
\end{tabular}

Precise analysis of the XRD patterns obtained for this alloy sintered at different temperatures revealed that with increasing the sintering temperature, the absolute intensity (number of counts) of the tungsten peaks substantially decreases with increasing sintering temperatures, which implies the increased tungsten solubility in the matrix with temperature resulting in a pronounced solid solution strengthening.

Also, it can be clearly noticed that the position $2 \theta$, at which the diffraction of the tungsten peaks on certain crystallographic planes, is very slightly shifted to the right, consequently, the inter-planner spacing and lattice parameter of tungsten cubic lattice are decreased. This slight decrease of lattice parameter indicates a very limited solubility of tungsten in nickel. This fact is confirmed by the nature of solubility between tungsten and nickel shown in their binary equilibrium diagram as in Fig.(8), which clearly indicates a negligible solubility of nickel in tungsten, and a considerable solubility of tungsten in nickel.

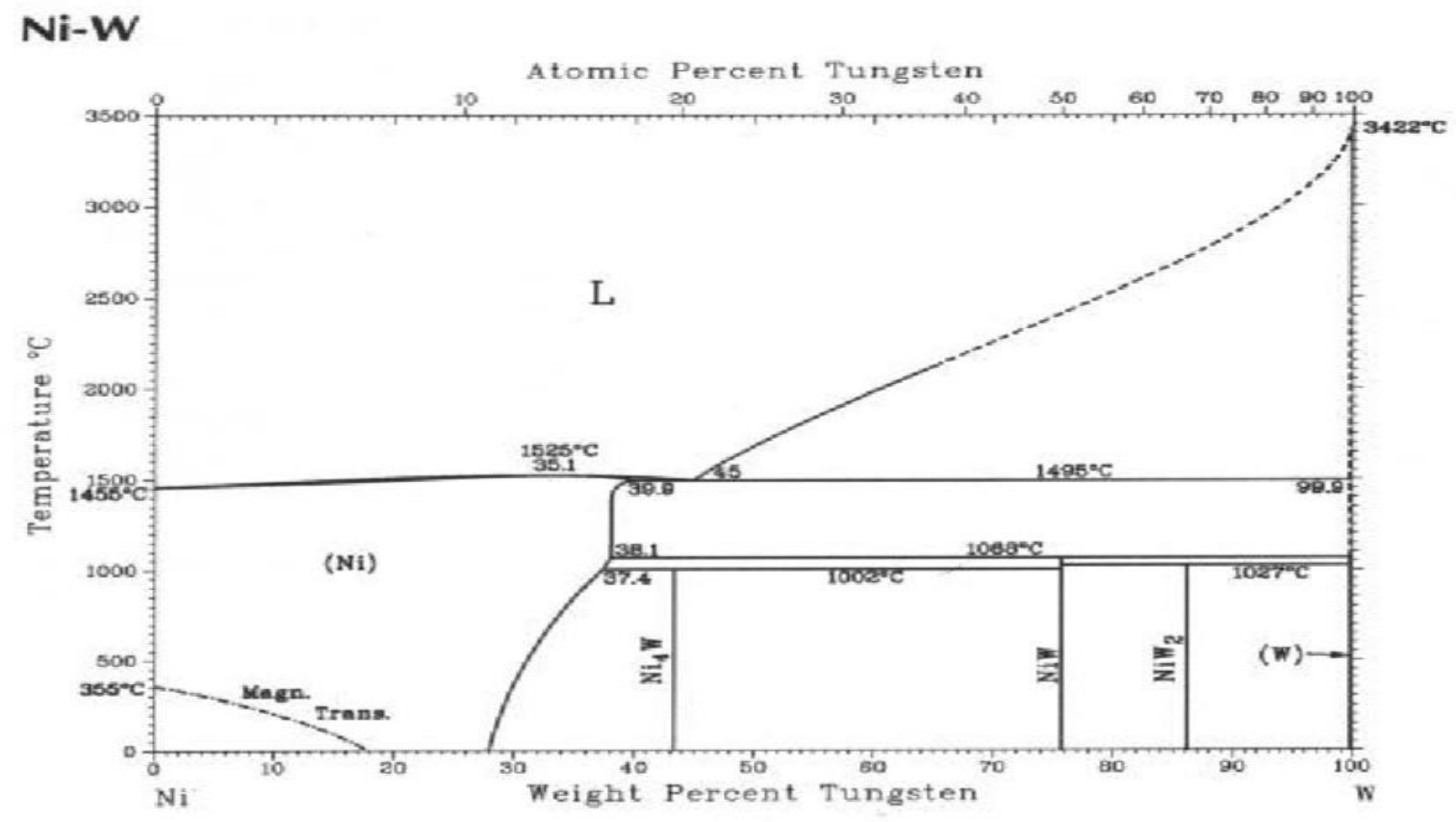

Fig 8: Binary phase diagram between tungsten and nickel [7]

\subsection{X-ray Diffraction Analysis for W-Ni-Fe and W-}

\section{Ni-Co Alloys}

Fig.(9) demonstrates the X-ray diffraction pattern obtained using tungsten heavy alloy having the composition $91 \% \mathrm{~W}$ $6 \% \mathrm{Ni}-3 \% \mathrm{Co}$ uni-axially compacted at $200 \mathrm{MPa}$ and sintered for 90 minutes at $1510^{\circ} \mathrm{C}$. This pattern reveals the co-existence of three series of peaks corresponding to three different phases, the first series of peaks correspond to the
W-BCC structure, and the second series correspond to the FCC structure of the binder phase. This binder phase is a solid solution with nickel as a host lattice and both cobalt and tungsten as guest atoms, while the third series refers to the formation of an intermetallic compound between tungsten and cobalt having the composition $\left(\mathrm{Co}_{3} \mathrm{~W}\right)$. 


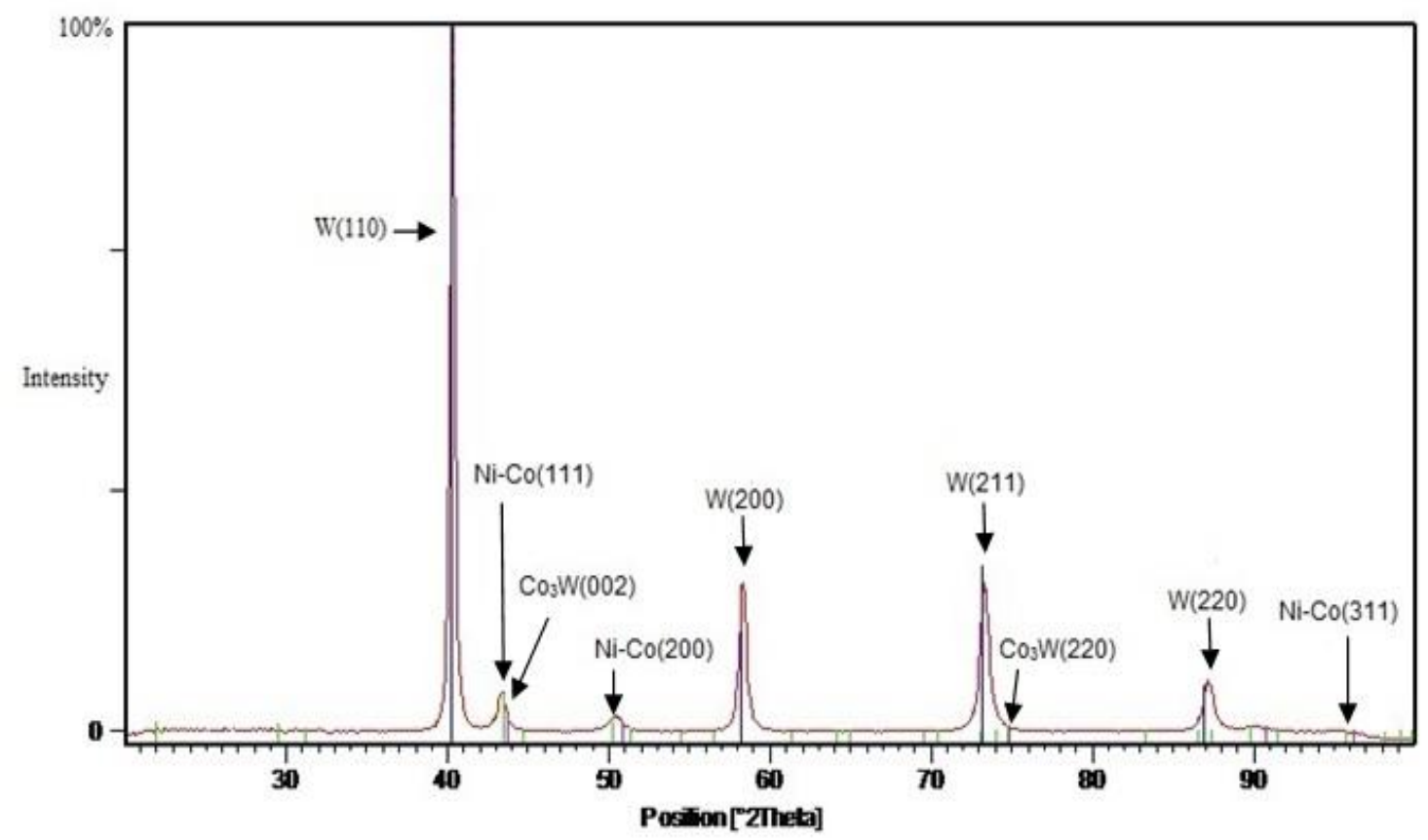

Fig 9: X-ray diffraction pattern obtained using tungsten heavy alloy having the composition $91 \% \mathrm{~W}-6 \% \mathrm{Ni}-3 \% \mathrm{Co}$ uni-axially compacted under $200 \mathrm{MPa}$ and sintered for 90 minutes at $1510^{\circ} \mathrm{C}$.

The obtained diffraction peaks and their corresponding position $2 \theta$ obtained for W-Ni-Co based heavy alloy together with their relative intensities are shown in Table (9).

Table 9: Diffraction results obtained from W-Ni-Co sintered at $1510^{\circ} \mathrm{C}$

\begin{tabular}{|c|c|c|c|c|}
\hline No. & Phase & Diffraction plane & Position $2 \theta$ & $\begin{array}{l}\text { Relative } \\
\text { intensity \% }\end{array}$ \\
\hline 1 & $\mathrm{~W}$ & 110 & 40.2821 & 100 \\
\hline 2 & $\mathrm{Ni}-\mathrm{Co}$ & 111 & 43.4348 & 5.28 \\
\hline 3 & $\mathrm{Co}_{3} \mathrm{~W}$ & 002 & 43.91 & 12 \\
\hline 4 & $\mathrm{Ni}-\mathrm{Co}$ & 200 & 50.2843 & 2.08 \\
\hline 5 & $\mathrm{~W}$ & 200 & 58.2637 & 20.47 \\
\hline 6 & $\mathrm{~W}$ & 211 & 73.2306 & 20.72 \\
\hline 7 & $\mathrm{Co}_{3} \mathrm{~W}$ & 220 & 74.99 & 5 \\
\hline 8 & $\mathrm{~W}$ & 220 & 87.1319 & 6.92 \\
\hline 9 & $\mathrm{Ni}-\mathrm{Co}$ & 311 & 95.2811 & 0.05 \\
\hline
\end{tabular}

The comparison of the absolute intensities of the tungsten diffraction peaks in the two alloys $93 \% \mathrm{~W}-4.9 \% \mathrm{Ni}-2.1 \% \mathrm{Fe}$ and $91 \% \mathrm{~W}-6 \% \mathrm{Ni}-3 \% \mathrm{Co}$ shown in Fig.(10), indicates that the absolute intensities of these peaks, in the case of the alloy with cobalt, is significantly higher than that in the case of the alloy with iron, although the tungsten content is lower in this alloy. This directly indicates that tungsten solubility in the Ni-Co matrix is lower than this solubility in the alloy having Ni-Fe matrix. Consequently, this result proves that the presence of cobalt in the solid solution of the matrix substantially suppresses the solubility of tungsten in this matrix. In fact, nickel and cobalt have higher mutual solubility than nickel and iron which influence further solubility of tungsten. 


\section{Intensity of Tungsten peaks in the alloy (W-Ni-Co) relative to those of the alloy (W-Ni-Fe)}

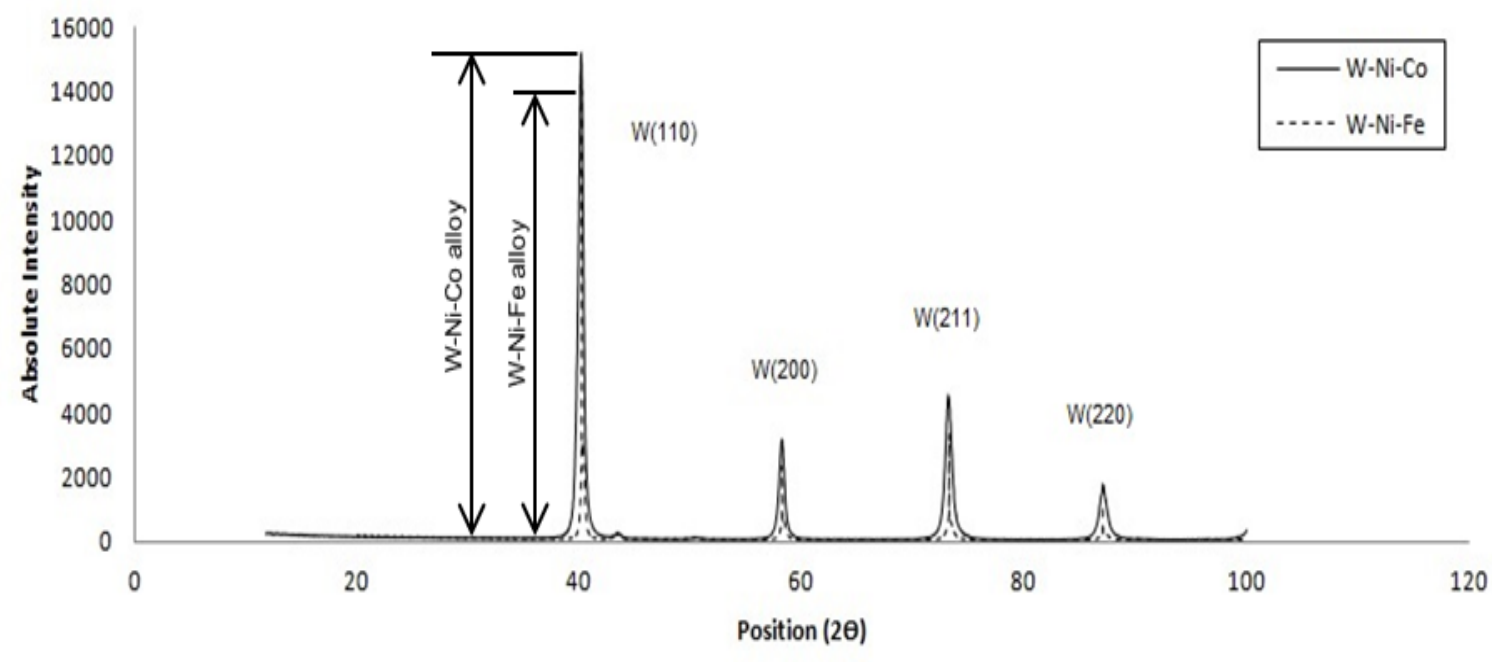

Fig 10: Comparison between the absolute intensity of peaks of the tungsten phase in the tungsten heavy alloys $91 \% \mathrm{~W}-6 \% \mathrm{Ni}$ $3 \% \mathrm{Co}$ and $93 \% \mathrm{~W}-4.9 \% \mathrm{Ni}-2.1 \% \mathrm{Fe}$ uni-axially compacted under $200 \mathrm{MPa}$ and sintered for 90 minutes at $1510^{\circ} \mathrm{C}$.

This result is in accordance with other researches [10] that refer to the effect of some alloying elements that have important solubility in the matrix thus reducing tungsten solubility. It was reported by A.Bose et al. [10] that cobalt has a sensible effect on reducing the solubility of tungsten in the matrix alloy and promotes the formation of tungsten inermetallic precipitate. On the other hand this reduced solubility of tungsten diminishes the reprecipitation process which consequently leads to hindering tungsten grain growth and, consequently improving microstructural refinement of the alloy [10].

We can conclude that cobalt addition to the matrix alloy has a very beneficial effect in strengthening the matrix of these alloys, by its high solubility in nickel, and also in refining the tungsten grains. On the other hand, cobalt has a strong affinity to form several intermetallic compounds with tungsten that usually precipitates along the interfacial boundary between tungsten grains and the matrix leading to a serious embrittlement effect. Thus, when cobalt is recommended to be added to get its utmost benefit, a post heat treatment process should be recommended in order to dissolve and prevent its formation.

\section{CONCLUSION}

Precise analysis of the XRD patterns obtained for W-Ni-Fe alloy sintered at different temperatures and after substituting iron with cobalt revealed that:

- The absolute intensity of the tungsten diffraction peaks decreases with increasing sintering temperatures, which implies the increased tungsten solubility in the matrix with temperature, resulting in a pronounced solid solution strengthening.

- The absolute intensities of tungsten diffraction peaks, in the case of the alloy with cobalt, is significantly higher than that in the case of the alloy with iron, although the tungsten content is lower in this alloy. Which indicates that tungsten solubility in the Ni-Co matrix is lower than this solubility in the alloy having Ni-Fe matrix. Consequently, this result proves that the presence of cobalt in the solid solution of the matrix suppresses the solubility of tungsten in this matrix. So, Cobalt serves as grain growth inhibitor (grain size refiner) as it hinders the diffusion of tungsten atoms, and consequently the processes of grain growth.

\section{REFERENCES}

[1]. Anish Upadhyaya, "Processing strategy for consolidating tungsten heavy alloys for ordnance applications", Materials Chemistry and Physics, Vol.67, pp. 101-110, 2001.

[2]. W.Leonard, L.Magness Jr. and D.Kapoor, "Improving mechanical properties of tungsten heavy alloy composites through thermo-mechanical processing", Tungsten and tungsten alloys, edited by A.Bose and R.J.Dowding. MPIF, Princeton, NJ., pp.127, 1992.

[3]. Heung Sub Song et al., "The effect of Ni/Fe ratio on the mechanical properties for tungsten heavy alloys", Advanced in powder metallurgy and particulate materials, pp. 77-93, 1992.

[4]. Penrice et al., "High density tungsten-nickel-iron-cobalt alloys having improved hardness and methods for making same", U.S patent, Patent number 4,762,559, Aug.1988.

[5]. B.H.Rabin, A.Bose and R.M.German, "Characteristics of liquid phase sintered tungsten heavy alloys", International journal of powder metallurgy, Vol.25, No.1, pp. 21, 1980. [6]. K.F.Ryen and R.J.Dowding, "Yield properties of tungsten and tungsten heavy alloys", ARL-TR-143, Army Research Laboratory, Watertown, MA.

[7]. ASM Handbook, "Alloy phase diagrams", Vol.3. 
[8]. H.K.Yoon, S.H.Lee, L.Kang, D.N.Yoon, "Effect of vacuum-treatment on mechanical properties of W-Ni-Fe heavy alloy", Journal of materials science, Vol.18, pp. 13741380, 1983.

[9]. A.S.Abdallah, A. Fayed, G.Abdou, M.Tolba Sallam, "Effect of processing parameters on the mechanical and structure properties of $93 \mathrm{~W}-4.9 \mathrm{Ni}-2.1 \mathrm{Fe}$ Tungsten heavy alloy", Fifteenth International Conference on Aerospace Sciences \& Aviation Technology, ASAT-15, MTC, Cairo, 2013.

[10]. A.Bose and R.M.German, "Microstructural Refinement of W-Ni-Fe Heavy Alloys by Alloying Additions", Metallurgical Transactions A, Vol. 19A, p.3100-3103, December 1988. 